\title{
Discrimination of Different Hop Varieties Using Headspace Gas Chromatographic Data
}

\author{
Katia Jorge and Luiz, C. Trugo* \\ Instituto de Química, Universidade Federal do Rio de Janeiro, CT, Bloco A, lab. 528, Ilha do Fundão, \\ 21949-900 Rio de Janeiro - RJ, Brazil
}

\begin{abstract}
Os métodos utilizados para caracterização do lúpulo envolvem a análise de substâncias amargas e do óleo essencial, seguida da comparação da composição química e perfis cromatográficos. No presente trabalho, diferentes variedades e produtos de lúpulo foram discriminados através da análise da composição dos óleos essenciais por cromatografia a gás no modo headspace em fase gasosa, com subsequente tratamento estatístico. Diferenças e similaridades foram determinadas em amostras provenientes dos Estados Unidos, da Nova Zelândia e da Europa, usando-se análise de correlações e "cluster". Os lúpulos com características de aroma apresentaram baixos níveis de mirceno, enquanto aqueles com características de amargor apresentaram altos teores de $\beta$-cariofileno e aloaromadendreno bem como as somas das razões dos marcadores escolhidos, independentemente de estarem sob a forma de "pellets" ou de extratos. Amostras altamente correlacionadas entre si e sem diferenças estatísticas mostram boa possibilidade para substituições entre elas, na produção da cerveja.
\end{abstract}

Methods for characterization of hop varieties include analyses of bitter acids and essential oils, followed by comparison of the chemical composition, particularly chromatographic profiles. In the present work discrimination of different hop varieties was carried out based on their essential oil volatile composition, assessed by headspace gas chromatography, with subsequent statistical treatment of the data. Differences and similarities were determined in samples from USA, New Zealand and Europe, using correlation and cluster analysis. Aroma hops presented low levels of myrcene while bitter samples showed high levels of $\beta$-caryophyllene, aloaromadendrene and also the sum of the marker ratios, independently of being in the form of pellets or extracts. Highly correlated samples with no significant differences have good possibility to substitute each other in the beer manufacture.

Keywords: hop aroma, hop products, beer, headspace-GC analysis

\section{Introduction}

The composition of hop (Humulus lupulus L.) essential oil has been studied extensively using many different analytical techniques for the separation and identification of the volatile organic compounds. Many methods described in the literature claim advantages and disadvantages between procedures including different extraction techniques. ${ }^{1-3}$ Loss of relevant volatiles during steam distillation extraction was well documented. ${ }^{4}$ Although headspace techniques have been recommended to avoid artefacts, the difficulties to obtain quantitative data by using this method has been also pointed out. ${ }^{5}$ However, it is well accepted that the headspace technique allows the analysis of a high number of samples in a relative short time allied to rapid and simple sample preparation procedures and it is

\footnotetext{
*e-mail: lctrugo@iq.ufrj.br
}

easily automated. The static headspace gas chromatography, sometimes called direct headspace sampling, is based on the thermodynamic equilibrium between the mixture of volatiles above the sample and the sample itself. When this equilibrium is achieved, generally by closing the sample into a vial which is thermostated in a chosen temperature, an aliquot of the volatile fraction is injected onto the GC column. ${ }^{6}$ The advance in automatic instrumentation for the injection of headspace samples has allowed a substantial increase in precision of the overall procedure.

In the present work statistical treatment of chromatographic data of hop products was applied for comparison of similarities between different samples. Headspace gas chromatography (HSGC) with automatic injection was used for the analysis of the hop products. The areas of the chromatographic peaks from different samples were compared and treated by correlation and cluster statistical analysis in order to determine significant differences between the chromatographic profiles and also to group 
similar samples that could be interchanged in beer processing.

\section{Materials and Methods}

\section{Samples}

Commercial hop samples were used for this study. Twelve samples were in the form of pellets, one as hexane extract, and nine as $\mathrm{CO}_{2}$ extracts. The samples from New Zealand were provided by New Zealand Hop (Richmond, New Zealand), the German samples were obtained from John Barth \& Sohn GmbH (Wurzburg, Germany) and the American samples were gifts from a Brazilian beer company. Their characteristics are shown in Table 1.

Table 1. Characteristics of the hop products

\begin{tabular}{|c|c|c|c|}
\hline Origin & Product form & Number & Variety \\
\hline Germany & $\mathrm{CO}_{2}$ extract & 1 & Tettnang Hallertauer \\
\hline Germany & $\mathrm{CO}_{2}$ extract & 2 & $\begin{array}{l}\text { Hallertau Brewers } \\
\text { Gold }\end{array}$ \\
\hline Germany & $\mathrm{CO}_{2}$ extract & 3 & $\begin{array}{l}\text { Hallertau Hallertauer } \\
\text { Tradition }\end{array}$ \\
\hline Germany & $\mathrm{CO}_{2}$ extract & 4 & $\begin{array}{l}\text { Hallertau Spalter } \\
\text { Select }\end{array}$ \\
\hline Germany & $\mathrm{CO}_{2}$ extract & 5 & $\begin{array}{l}\text { Slowenischer Super } \\
\text { Steirer }\end{array}$ \\
\hline Germany & $\mathrm{CO}_{2}$ extract & 6 & $\begin{array}{l}\text { Hallertau Hallertauer } \\
\text { Magnum }\end{array}$ \\
\hline Germany & $\mathrm{CO}_{2}$ extract & 7 & $\begin{array}{l}\text { Hallertau Northern } \\
\text { Brewer }\end{array}$ \\
\hline New Zealand & Pellets (T45) & 8 & NH Hallertau Aroma \\
\hline New Zealand & Pellets (T45) & 9 & Sticklebract \\
\hline New Zealand & Pellets (T45) & 10 & Southern Cross \\
\hline New Zealand & Pellets (T45) & 11 & Super Alpha \\
\hline New Zealand & Pellets (T45) & 12 & Green Bullet \\
\hline New Zealand & Pellets (T45) & 13 & Pacific Gem \\
\hline Germany & Pellets (T90) & 14 & Saaz \\
\hline Germany & Pellets (T90) & 15 & Hallertau Perle \\
\hline Germany & Pellets (T90) & 16 & Saaz \\
\hline USA & Pellets (T90) & 17 & Cluster \\
\hline USA & Pellets (T90) & 18 & Cluster \\
\hline USA & Hexan extract & 19 & Cluster \\
\hline USA & Pellets (T90) & 20 & Cluster \\
\hline USA & $\mathrm{CO}_{2}$ extract & 21 & Nugget \\
\hline USA & $\mathrm{CO}_{2}$ extract & 22 & Galena \\
\hline
\end{tabular}

The samples were stored under nitrogen and refrigeration in dark flasks. Before analysis they were left to reach room temperature and were weighed $(1.0 \mathrm{~g})$ directly in the headspace vials. The vials were assembled directly into the GC headspace automatic injector.

\section{GC analysis}

Gas chromatography was carried out using a Shimadzu
17-A equipment fitted with a HSS-4AE headspace automatic sampler and a C-R7A data processor (Kyoto, Japan). A polyethylene glycol fused silica capillary column from Supelco (Bellefonte, PA, USA) with $50 \mathrm{~m} \mathrm{x}$ $0.25 \mathrm{~mm}$, i.d., and $0.25 \mu \mathrm{m}$ of film thickness was used. The oven temperature program started at $50{ }^{\circ} \mathrm{C}$ for $10 \mathrm{~min}$, increased to $80{ }^{\circ} \mathrm{C}$ at $2{ }^{\circ} \mathrm{C} \mathrm{min}-1$ and then to $200{ }^{\circ} \mathrm{C}$ at $4{ }^{\circ} \mathrm{C} \mathrm{min}{ }^{-1}$, held for $10 \mathrm{~min}$. The headspace temperature was kept at $110^{\circ} \mathrm{C}$ for $30 \mathrm{~min}$ previous to the injection of $5 \mathrm{~mL}$ of the headspace gas into the column. The injector and detector temperatures were $150{ }^{\circ} \mathrm{C}$ and $250{ }^{\circ} \mathrm{C}$, respectively. The carrier gas was hydrogen, at a flow rate of $1.6 \mathrm{~mL} \mathrm{~min}^{-1}$ and the split ratio was 1:30. Identification of marker compounds was carried out by comparison and spiking with external standards. Myrcene, $\alpha$-limonene, $\beta$ caryophyllene, aloaromadendrene, linalool and $\alpha$ humulene from Carl Roth GmbH (Karlsruhe, Germany) were used as standards.

\section{Statistical analysis}

The areas of the 50 major chromatographic peaks of all samples were considered for the statistical treatment. Cluster Analysis was applied by using a Statgraphics software (Bitstream Inc., Cambridge, MA, USA). Pearson correlation with paired $t$-test was applied by using a MS EXCEL software (Microsoft Co., Bellevue, WA, USA).

\section{Results and Discussion}

The peak areas of the chromatograms obtained by HSGC were used to spot differences between the samples. Figure 1 shows some examples of chromatograms obtained from the samples studied. As it has been commonly applied by other authors, ${ }^{7} \alpha$-humulene was used as reference because it is encountered in all hop samples. Consequently, the area of all chromatographic peaks were then normalized relatively to $\alpha$-humulene. Reproducibility of data obtained by the HSGC method was very good. The higher coefficient of variation of the relative peak areas was $12.7 \%$, which appears to be quite acceptable in terms of the overall precision normally encountered in headspace chromatographic methods. The use of marker compounds to simplify the analysis of the complex chromatographic data from hop volatiles has been applied to compare the quality of hop varieties. ${ }^{8}$ In the present work five markers (myrcene, $\alpha$-limonene, $\beta$-caryophyllene, aloaromadendrene and linalool) were identified in all samples. Sample 19 showed highest peak areas for myrcene, $\alpha$-limonene, $\beta$-caryophyllen and aloaromadendrene and these areas were used as denominator to calculate the ratios of those markers in all 
samples, following the procedure of De Keukeleure. ${ }^{8}$ Linalool showed the highest area in sample 4 and consequently, it was used as denominator for linalool ratios

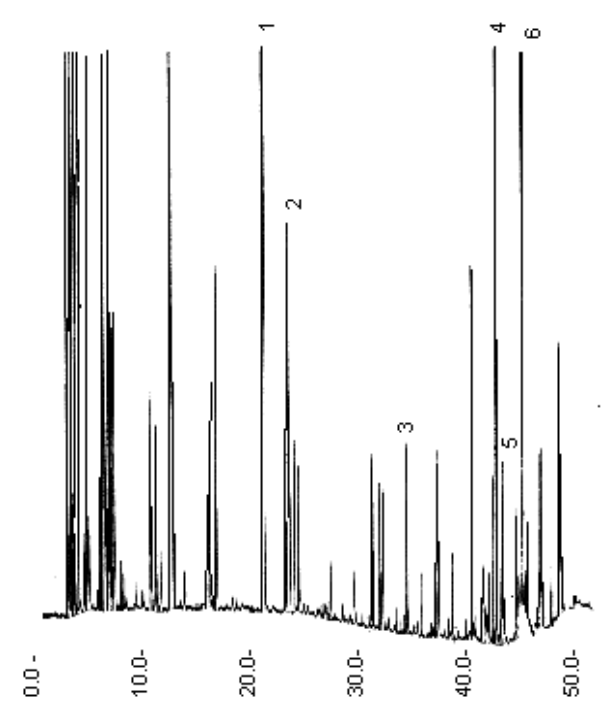

time / min

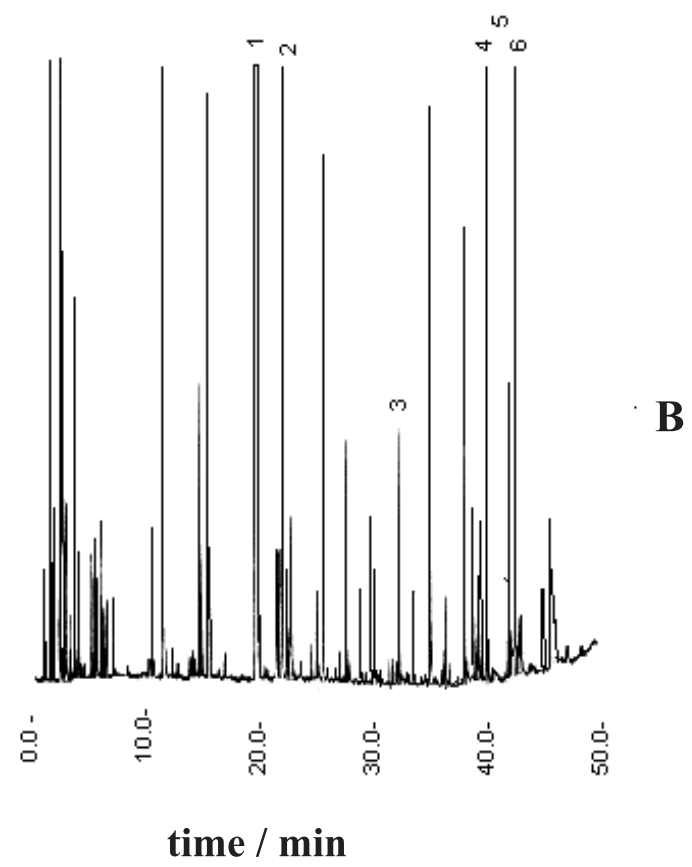

Figure 1. Headspace gas chromatograms of hop volatiles. A polyethylene glycol fused silica capillary column $(50 \mathrm{~m} \times 0.25 \mathrm{~mm}$, i.d.) was used. Other conditions were described in Materials and Methods. A) Perle hop in the form of pellets; B) Cluster hop in the form of pellets. Peaks: 1 , myrcene; 2, $\alpha$-limonene; 3 , linalool; $4, \beta$ caryophyllene; 5, aloaromadendrene; $6, \alpha$-humulene. in all samples. The results are shown in Table 2. Both the individual and the sum of the ratios of each sample provided a qualitative and quantitative profile for characterization of the samples, because the predominance of specific ratios are indicative of the hop characteristic showing that the hop product will contribute more to the aroma or to the flavour of the final product.

Hop varieties such as Saaz, Perle and Cluster are considered to be some of the most important commercially. Saaz and Perle being typical hop materials while Cluster a hop variety with predominant bitter characteristics. Similar patterns were obtained for samples belonging to the same group of bitter or aromatic products. However, marked differences were detected within groups if samples were in the form of pellets or extract. Sample number 19, which is an extract from a Cluster variety, was completely different from their similar pellet samples, showing higher amounts of all markers except linalaol. However, well known aroma hops such as Saaz and Perle (samples 14 to 16) showed consistently low myrcene content while bitter hops such as Cluster (samples 17 to 20) were richer in $\beta$ caryophyllene, aloaromadendrene and also in the sum of the marker ratios (Table 2).

The statistical treatment of the chromatographic data obtained from the volatile profiles allowed to group samples which presented similar characteristics as a whole. A tree diagram with weighted pair group average for the 22 samples shows their hierarchic distribution forming defined groups of aroma and bitter varieties (Figure 2). The pellet samples formed basically two groups (samples $20,17,18,15,16,14,11$ and $13,12,10$ ) while the extracts formed a major group of bitter type hops (samples 19, 22, $5,4,21,7,6)$. The New Zealand hops Pacific Gem, Green Bullet and Southern Cross, which show both bitter and aroma characteristics were closer grouped (samples 13, 12 and 10, respectively). Some pair of samples with different characteristics such as 18 and 15 (bitter and aroma, respectively) and 8 and 2 (both aromatic and bitter and bitter, respectively) appears to have mixed properties and may produce similar results in the end product. Sample 3 was grouped together with other Hallertau hop types while sample 9, which is a Sticklebrast variety showed similarities to sample 1, which is a Tettnang Hallertauer type, in the tree diagram.

Because samples 14 to 18 are some of the most commercially important hop products they were selected to determine their correlations with the remaining samples. The statistical comparison of hops of the Saaz variety (14 and 16) and Perle (15) which have strong aroma characteristics, with the other samples allowed the selection of highly correlated samples which could be potentially useful 
Table 2. Ratios of the areas of the chromatographic peaks of marker compounds of the hop samples ${ }^{\mathrm{a}}$

\begin{tabular}{lcccccc}
\hline Sample $^{\mathrm{b}}$ & Myrcene & $\alpha$-Limonene & $\beta$-Caryophyllene & Aloaromadendrene & Linalool & Sum of ratios \\
\hline 1 & 0.26 & 0.13 & 0.66 & 0.38 & 0.65 & 2.08 \\
2 & 0.44 & 0.89 & 0.85 & 0.46 & 0.46 & 3.10 \\
3 & 0.39 & 0.33 & 0.50 & 0.73 & 0.44 & 2.39 \\
4 & 0.56 & 0.28 & 0.14 & n.d. & 1.90 \\
5 & 0.61 & 0.30 & 0.58 & 0.27 & 0.52 & 2.28 \\
6 & 0.41 & 0.35 & 0.61 & 0.19 & 0.13 & 1.69 \\
7 & 0.41 & 0.32 & 0.68 & 0.15 & 0.13 & 1.69 \\
8 & 0.44 & 0.17 & 0.82 & 0.38 & 0.21 & 2.02 \\
9 & 0.29 & 0.86 & 0.86 & 0.54 & 0.40 & 2.41 \\
10 & 0.26 & 0.62 & 0.61 & 0.27 & 0.58 & 2.61 \\
11 & 0.08 & 0.16 & 0.59 & $n .4 .^{c}$ & 0.33 & 1.43 \\
12 & 0.25 & 0.86 & 0.64 & 0.23 & 0.38 & 2.31 \\
13 & 0.21 & 0.72 & 0.68 & 0.31 & 0.21 & 1.99 \\
14 & 0.01 & 0.12 & 0.58 & 0.19 & 0.27 & 1.15 \\
15 & 0.01 & 0.45 & 0.68 & 0.54 & 0.13 & 1.72 \\
16 & 0.01 & 0.11 & 0.57 & 0.65 & 0.42 & 1.01 \\
17 & 0.06 & 0.46 & 0.74 & 1.00 & 0.23 & 2.22 \\
18 & 0.01 & 0.53 & 0.69 & 0.96 & 0.19 & 2.11 \\
19 & 1.00 & 1.00 & 1.00 & 0.31 & 0.46 & 4.19 \\
20 & 0.04 & 0.88 & 0.62 & 0.50 & 0.42 & 2.96 \\
21 & 0.40 & 0.37 & 0.89 & 0.21 & 2.39 \\
22 & 0.66 & 0.69 & 0.92 & &
\end{tabular}

a The areas of the peaks correspondent to myrcene, $\alpha$-limonene, $\beta$-caryophyllene and aloaromadendrene from all samples were divided by the areas of the same compounds present in sample 19 which showed their highest levels of these compounds. The peak areas correspondent to linalool from all samples were divided by the area of the same compound present in sample 4 which showed the highest value, following the procedure described by De Keukeleure ${ }^{8}{ }^{\mathrm{b}}$ The hop varieties corresponding to the numbers in the first column of the table are described in Table $1 ;{ }^{c}$ n.d. $=$ not detected.

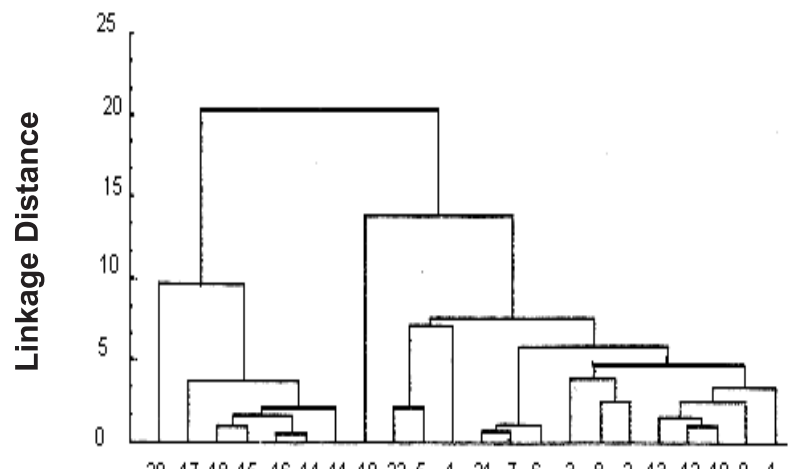

Samples

Figure 2. Tree diagram for 22 variables obtained by statistical treatment of the peak areas of the headspace gas chromatograms of the hop samples. Diagram shows weighted pair-group average and Euclidean distances.

for substitution in beer formulation. Similarly, confronting Cluster hops (15 and 18), which have bitter characteristics, with the other samples it is possible to choose strongly correlated products in relation to their bitter characteristics (Table 3).

It is important to notice that some samples were not statistically correlated but were statistically similar while others were highly correlated but were significantly
Table 3. Pearson correlation of commercially important hop varieties with other hop samples

\begin{tabular}{llllll}
\hline Samples & 14 & 15 & 16 & 17 & 18 \\
\hline 1 & 0.75 & 0.76 & $0.75^{\mathrm{a}}$ & 0.84 & 0.76 \\
3 & 0.69 & 0.70 & 0.69 & 0.78 & 0.70 \\
9 & 0.64 & 0.67 & 0.64 & 0.76 & 0.67 \\
10 & 0.62 & 0.64 & 0.62 & 0.72 & 0.63 \\
11 & 0.95 & 0.95 & 0.95 & $0.96^{\mathrm{a}}$ & 0.94 \\
12 & 0.62 & 0.65 & 0.62 & 0.72 & 0.65 \\
13 & 0.65 & 0.68 & 0.65 & 0.74 & 0.67 \\
14 & 1.00 & $0.99^{\mathrm{a}}$ & 1.00 & $0.96^{\mathrm{a}}$ & $0.98^{\mathrm{a}}$ \\
15 & $0.99^{\mathrm{a}}$ & 1.00 & $0.98^{\mathrm{a}}$ & 0.97 & 0.99 \\
16 & 1.00 & $0.99^{\mathrm{a}}$ & 1.00 & $0.95^{\mathrm{a}}$ & 0.98 \\
17 & $0.96^{\mathrm{a}}$ & 0.97 & $0.96^{\mathrm{a}}$ & 1.00 & 1.00 \\
18 & $0.98^{\mathrm{a}}$ & 0.99 & $0.97^{\mathrm{a}}$ & 0.98 & 1.00 \\
19 & 0.12 & 0.14 & 0.12 & 0.26 & 0.12 \\
20 & $0.95^{\mathrm{a}}$ & 0.96 & 0.95 & $0.99^{\mathrm{a}}$ & $0.95^{\mathrm{a}}$ \\
21 & 0.21 & 0.23 & 0.21 & 0.34 & 0.21 \\
22 & 0.17 & 0.19 & 0.17 & 0.30 & 0.17 \\
\hline
\end{tabular}

Chromatographic peak areas were used for paired t-test compari-

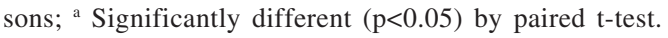

different. The high correlated samples which also showed no significant differences, namely 11 with $14,15,16$ and $18 ; 15$ with 17, 18 and 20; and 16 with 14, 18 and 20, are good possibilities to replace each other in beer formulation.

The establishment of similarities of groups of hop samples with aromatic and bitter characteristics, inde- 
pendently of the manufacturing process, may be helpful for the beer industry since these data may assist on the decision to acquire the better priced and most easily available hop products in the market which could substitute specific ones commonly used in the production of specific beers. The results of the present work are useful for the selection of hop products and also to direct a complementary investigation to determine the sensorial impact of chemically similar hop ingredients in a formulated beer.

\section{Acknowledgements}

CNPq, CAPES and FAPERJ (Brazil) are acknowledged for financial support. We also thank Dr F. Knudsen and A. Steinberg for providing samples.

\section{References}

1. Wright, R.G.; Connery, F.R.; ASBC Proceedings 1951, 87, 425.

2. Maier, J.; Mschr. Brauwiss. 1966, 19, 425.

3. Seeleitner, G.; Seif, P.; Püspök, J.; Mschr Brauwiss. 1985, 38,

4. Krüger, E.; Neumann, L.; Monatsschrift für Brauerei 1970, $23,269$.

5. Narziss, L.; Foster, A.; Mschr. Brauwiss. 1970, 23, 289.

6. Wu, Y.; Hamouz, F.; Schnepf, M.; J. Agric. Food Chem. 1998, 46, 3677.

7. Freundorfer, J.; Maier, J.; Reiner, L.; Monatsschrift für Brauwissenschaft 1991, 5, 176.

8. De Keukeleure, D.; J. Inst. Brew. 1998, 104, 75.

Received: March 21, 2002

Published on the web: May 8, 2003 